\title{
PERFIL DE TEXTURA E CAPACIDADE DE RETENÇÃo DE ÁGUA DE GÉIS ÁCIDOS DE CONCENTRADO PROTÉICO DE SORO DE LEITE ${ }^{1}$
}

\author{
Adriane Elisabete Costa ANTUNES ${ }^{2, *}$, Eliana Maria Pettirossi MOTTA ${ }^{3}$, Aloísio José ANTUNES ${ }^{4}$
}

\section{RESUMO}

A capacidade dos concentrados protéicos de soro de leite (CPS) de formar géis é importante propriedade funcional. O objetivo deste estudo foi avaliar a influência das variáveis concentração de proteína, pH, temperatura e tempo de desnaturação, nos intervalos de 8 a $12 \% ; 4,0$ a 5,$2 ; 81$ a $89^{\circ} \mathrm{C}$ e 15 a 27 minutos, respectivamente, no perfil de textura e capacidade de retenção de água de géis ácidos de CPS. O perfil de textura foi determinado em texturômetro TAXT2 e a capacidade de retenção de água avaliada através da umidade espremivel dos géis. O delineamento estatístico foi um planejamento fatorial $2^{4}$ completo. Os géis de CPS apresentaram os maiores valores de firmeza, coesividade, elasticidade e capacidade de retenção de água, de maneira geral, nas maiores faixas de concentração protéica, tempo e temperatura de desnaturação. Com relação a variável pH, géis formados em pH 4,0 apresentaram-se mais elásticos e com maior capacidade de retenção de água, enquanto que os géis formados em pH 4,9 a 5,2 mostraram-se mais firmes e coesos.

Palavras-chave: concentrado protéico de soro de leite; gel; textura; retenção de água.

\section{SUMMARY}

TEXTURE PROFILE AND WATER-HOLDING CAPACITY OF WHEY PROTEIN CONCENTRATE ACID GELS. The ability of whey protein concentrates (WPC) to form gel structures is an important functional property. The aim of this study was to evaluate protein concentration, $\mathrm{pH}$, temperature and denaturation time, at 8 to $12 \%, 4.0$ to $5.2,81$ to $89^{\circ} \mathrm{C}$ and 15 to 27 minutes, respectively, on texture profile and water-holding capacity of WPC acid gels. The texture profile was evaluate by a texturometer TAXT2 and water-holding capacity by expressible moisture. The statistic method applied was the factorial $2^{4}$ planning. The best results of strength, cohesivity, springiness and water-holding capacity were generally obtained with the higher levels of protein concentration, temperature and denaturation time. Concerning the variable $\mathrm{pH}$, the range from 4.0 to 4.3 led to formation of gels with higher elasticity and water-holding capacity, while samples prepared at $\mathrm{pH} 4.9$ to 5.2 developed gels with higher hardness and cohesivity.

Keywords: whey protein concentrate; gel; texture; water-holding capacity.

\section{1 - INTRODUÇÃO}

Os concentrados protéicos de soro de leite (CPS) são sistemas multifuncionais que vêm sendo adicionados a diversos alimentos, com o objetivo de modificar propriedades através de gelatinização, aumento de viscosidade, estabilização de emulsões ou espumas, entre outros.

A capacidade das proteinas do soro de leite, quando em solução, de formar géis estáveis através do aquecimento é uma importante propriedade funcional [17]. A reação inicial do processo de gelatinização envolve o enfraquecimento e quebra das pontes de hidrogênio e dissulfidicas desestabilizando a estrutura conformacional das proteínas. Posteriormente, ocorre polimerização das moléculas de proteina produzindo uma estrutura tridimensional capaz de imobilizar fisicamente grande parte do solvente, através de ligações dissulfidicas intermoleculares, interações hidrofóbicas e iônicas [15]. A integridade fisica do gel é mantida pelo contrabalanceamento das forças de atração e repulsão entre as moléculas de proteína e destas com o solvente circundante [24].

1. Recebido para publicação em 22/11/2002. Aceito para publicação em 10/07/2003 (001007).

${ }^{2}$ Curso de Pós-Graduação em Alimentos e Nutrição, Lab. de Funcionalidade de Proteinas, FEA, UNICAMP, Caixa Postal 6017, CEP - 13083970,e-mail:adrica@fea.unicamp.br, telefone: (19) 3788-4069.

${ }^{3}$ Departamento de Planejamento Alimentar e Nutrição, FEA/UNICAMP, Caixa Postal 6017,CEP - 13083-970,e-mail: prtti@fea.unicamp,br.

${ }^{4}$ Departamento de Planejamento Alimentar e Nutrição, FEA/UNICAMP, Caixa Postal 6017,CEP - 13083-970,e-mail: aantunes@fea.unicamp,br. * A quem a correspondência deve ser enviada.
As propriedades dos géis de CPS induzidos termicamente são influenciadas por muitos fatores, tais como concentração de proteína, $\mathrm{pH}$, temperatura e duração do tratamento térmico [14]. Outros fatores, segundo KOHNHORT \& MANGINO [12] são interações iônicas, hidrofóbicas e sulfidrilas livres.

$\mathrm{O} \mathrm{pH}$, assim como a força iônica, pode alterar a distribuição das cargas entre as cadeias laterais das proteínas causando aumento ou diminuição das interações proteina-proteina [9]. O CPS é composto por quatro frações protéicas principais que apresentam pontos isoelétricos de 5,2 ( $\beta$-lactoglobulina), 4,2-4,5 ( $\alpha$-lactoalbumina), 4,7-4,9 (albumina do soro bovino) e 5,5-8,3 (imunoglobulinas). O aquecimento de soluções de CPS em valores de $\mathrm{pH}$ próximos ao ponto isoelétrico, leva a formação de coágulos túrbidos e sujeitos a sinérese devido às forças atrativas intensas entre as moléculas protéicas, resultando em géis frágeis e de reduzida elasticidade $[6,11,17]$.

Com o aumento da concentração protéica ocorre modificação da textura dos géis, resultando em aumento da firmeza e intensificando a retenção de água pela matriz [13, 21]. As proteinas do soro de leite que apresentam melhores propriedades gelatinizantes são a $\beta$-lactoglobulina e a albumina do soro bovino (BSA), mas sendo a primeira de 10 a 20 vezes mais abundante nos produtos com soro lácteo, pois ela é considerada a principal agente gelatinizante [1]. Essa propriedade deve-se a presença de grupos sulfidrilas livres [20]. 
Durante o aquecimento de soluções de CPS ocorre desnaturação das proteínas do soro, que são naturalmente globulares, expondo grupamentos reativos que poderão se envolver em ligações hidrofóbicas, pontes dissulfeto, interações iônicas e induzidas pelo cálcio; e durante o resfriamento formam-se principalmente pontes de hidrogênio [6]. A ordem aparente de desnaturação das principais proteínas do soro individualmente é: $\quad$ Ig $>$ BSA $>\beta$-lactoglobulina $>\alpha$ lactoalbumina; todavia as taxas de desnaturação são fortemente influenciadas por $\mathrm{pH}$, composição iônica e concentração de sólidos totais [17]. Temperaturas elevadas favorecem a formação de géis mais firmes [9]. No entanto, segundo os mesmos autores, o aumento da firmeza não é função linear da temperatura [9].

COOPER, HUGHES \& MATTHEWS [7], utilizando metodologia de superficie de resposta investigaram o efeito da concentração de proteínas do soro, e adição de $\mathrm{NaCl}, \mathrm{CaCl}_{2}$ e sacarose na formação de gel. BOYE, RAMASWANY \& RAGHAVAN [5], avaliaram o efeito do tempo e temperatura de aquecimento, $\mathrm{pH}$, concentração de $\mathrm{NaCl}$, sacarose e concentração de proteína de CPS, de marcas comerciais, nas caracteristicas de firmeza do gel e capacidade de retenção de água.

Grande parte dos trabalhos publicados sobre gelatinização das proteinas de CPS enfocou faixa de $\mathrm{pH}$ abaixo do ponto isoelétrico das proteínas do soro $[7,16,22,23]$ ou acima $[14,20,21,22,23]$. Neste trabalho, foi escolhida à faixa correspondente ao $\mathrm{pH}$ das principais proteinas do CPS $(4,0$ e 5,2$)$ para verificar seu comportamento quando aplicado na produção de alimentos ácidos, tais como iogurtes. O objetivo foi avaliar a influência da concentração de proteína, $\mathrm{pH}$, temperatura e tempo de desnaturação sobre perfil de textura e a capacidade de retenção de água dos géis ácidos de CPS.

\section{2 - MATERIAL E MÉTODOS}

\section{1 - Material}

Amostra comercial de concentrado protéico de soro de leite (CPS) Alacen ${ }^{\mathrm{TM}} 392$ foi adquirida da empresa New Zealand Milk Products $(78,56 \%$ de proteína, $5,96 \%$ de gordura, $2,62 \%$ de cinzas, $5,73 \%$ de umidade e $6,44 \%$ de lactose) e estocada a vácuo sob refrigeração $\left(5 \pm 2{ }^{\circ} \mathrm{C}\right)$. Este CPS foi obtido a partir de soro doce ( $\mathrm{pH}$ 6-6,2), ultrafiltrado, diafiltrado e seco em spray drying.

\section{2 - Métodos}

\subsection{1 - Gelatinização das proteínas de CPS}

Os géis de CPS foram preparados segundo metodologia sugerida por BEUSCHEL et al. [3], com concentração protéica variando entre 8 a $12 \%$, pH entre 4,0 a 5,2 e temperatura e tempo de desnaturação variando entre 81 a $89^{\circ} \mathrm{C}$ e 15 a 27 minutos, respectiva- mente. $\mathrm{O}$ ajuste de $\mathrm{pH}$ foi feito pela adição de $\mathrm{HCl} 1 \mathrm{~N}$. Para remover bolhas de ar, as soluções protéicas foram centrifugadas por 10 minutos em centrifuga Sorvall RC5C a 29 x g. Alíquotas de $10 \mathrm{~mL}$ de solução foram transferidas para tubos de vidro de $20 \mathrm{~mm}$ de diâmetro interno, vedados numa das extremidades por rolha de borracha e selados com plástico na outra extremidade. Após desnaturação térmica em banho-maria foram resfriadas em banho da água gelada por 5 minutos e armazenadas em geladeira $\left(7 \pm 3^{\circ} \mathrm{C}\right)$ por 20 horas. Os géis foram removidos dos tubos e amostras com $1 \mathrm{~cm}$ de altura foram cortadas em triplicata para determinação do perfil de textura.

\subsection{2 - Perfil de textura}

A análise do perfil de textura foi realizada segundo FRIEDMAN, WHITNEY \& SZCZESNIAK [8], utilizando texturômetro TA-XT2, com probe cilindrico de acrílico de fundo chato de $20 \mathrm{~mm}$ de diâmetro e os resultados obtidos da curva força $\mathrm{x}$ tempo foram calculados pelo programa Texture Expert versão 1.11 para TPA (Texture Profile Analysis). As condições de medida foram padronizadas em calibre do probe $40 \mathrm{~mm}$, força e velocidade de compressão de $5 \mathrm{~g}$ e $3 \mathrm{~mm} \cdot \mathrm{s}^{-1}$, respectivamente. No perfil de textura três caracteristicas de interesse para esse estudo foram utilizadas: dureza (ou firmeza), coesividade e elasticidade.

\subsection{3 - Capacidade de retenção de água}

A capacidade de retenção de água dos géis, que consiste na quantidade de liquido expelido de um sistema protéico pela aplicação de uma força centrífuga, foi avaliada por umidade espremivel (UE) segundo a metodologia proposta por JAUREGUI, REGENSTEIN \& BAKER [10], com modificações de BEUSCHEL et al. [3]. Amostras de gel $(1 \mathrm{~g} \pm 0,15)$ foram pesadas em papel filtro Whatman número 2 e centrifugadas a 700g (2500rpm em rotor SS34, centrifuga Sorvall RC5C) por 10 minutos a $6^{\circ} \mathrm{C}$. A porcentagem de umidade espremivel foi calculada através da diferença entre o papel de filtro seco e úmido. Quanto maior a umidade espremivel, ou seja, quanto maior a quantidade de liquido liberado, menor será a capacidade de retenção de água dos géis. A umidade espremivel dos géis é calculada pela fórmula a seguir:

$$
\% \text { U. E. }=\frac{[\text { peso }(g) \text { de água liberada x } 100]}{\text { peso do gel }(\mathrm{g})}
$$

\subsection{4 - Planejamento experimental}

Neste trabalho foi empregado um delineamento fatorial $2^{4}$ completo, com 4 variáveis independentes em 2 niveis eqüidistantes ( -1 e 1$)$, três repetições no ponto central (nivel 0 ) e acrescido de 8 pontos axiais $(-\alpha$ e $\alpha)$, onde $\alpha= \pm\left(2^{\mathrm{n}}\right)^{1 / 4}$, sendo $\mathrm{n}$ o número de variáveis independentes [19]. Os pontos experimentais foram analisados pela metodologia de superficie de resposta (RMS) segundo BOX \& DRAPER [4]. 
TABELA 1. Níveis e valores das variáveis independentes: concentração de CPS, pH, temperatura e tempo de desnaturação

\begin{tabular}{lcccccc}
\hline \multirow{2}{*}{ Variáveis independentes } & \multirow{2}{*}{ Codificadas } & \multicolumn{5}{c}{ Níveis } \\
\cline { 3 - 7 } Concentração proteína $(\%)$ & $\mathrm{P}$ & $-\propto$ & $\mathbf{- 1}$ & $\mathbf{0}$ & $\mathbf{1}$ & $\mathbf{+}$ \\
Temperatura $\left({ }^{\circ} \mathrm{C}\right)$ & $\mathrm{T}$ & 81 & 83 & 10 & 11 & 12 \\
Tempo (min) & $\mathrm{t}$ & 15 & 18 & 21 & 87 & 89 \\
$\mathrm{pH}$ & $\mathrm{pH}$ & 4,0 & 4,3 & 4,6 & 4,9 & 27 \\
\hline
\end{tabular}

Os niveis escolhidos das variáveis independentes concentração de proteína do soro de leite, $\mathrm{pH}$, temperatura e tempo de desnaturação encontram-se na Tabela 1.

\subsection{5 - Análise estatística}

Equações polinomiais de segunda ordem foram ajustadas para os dados experimentais. As variáveis não significativas a 95\% de confiança foram colocadas no resíduo. O software Statistica for Windows versão V foi utilizado para calcular os coeficientes de regressão, análise de variância (ANOVA) e coeficientes de correlação do modelo, bem como para gerar as superficies de resposta.

\section{3 - RESULTADOS E DISCUSSÃO}

Os valores codificados para os ensaios e as respostas do perfil de textura (firmeza, elasticidade e coesividade) e da capacidade de retenção de água (medida por umidade espremivel) dos géis de CPS, encontram-se sumarizados na Tabela 2. As respostas das variáveis dependentes estão expressas em valor médio de três repetições. A variabilidade associada aos testes foi pequena, sendo aceito coeficiente de variação menor de $5 \%$ para capacidade de retenção de água e de $10 \%$ para as medidas de textura (devido à alta sensibilidade do equipamento).

TABELA 2. Planejamento fatorial $2^{4}$ completo e respostas* de dureza, elasticidade, coesividade e capacidade de retenção de água dos géis de CPS

\begin{tabular}{|c|c|c|c|c|c|c|c|c|}
\hline \multirow[b]{2}{*}{ Ensaio } & \multicolumn{4}{|c|}{ Valores codificados } & \multicolumn{4}{|c|}{ Respostas } \\
\hline & $\mathrm{P}$ & $\mathrm{T}$ & $t$ & $\mathrm{pH}$ & $\begin{array}{c}\text { Dureza } \\
\text { (g) }\end{array}$ & $\begin{array}{c}\text { Elastici- } \\
\text { dade }^{1}\end{array}$ & $\begin{array}{l}\text { Coesivi- } \\
\text { dade }^{1}\end{array}$ & $\mathrm{UE}^{2}(\%)$ \\
\hline 1 & -1 & -1 & -1 & -1 & 31,77 & 0,706 & 0,288 & 73,04 \\
\hline 2 & 1 & -1 & -1 & -1 & 57,86 & 0,79 & 0,326 & 62,96 \\
\hline 3 & -1 & 1 & -1 & -1 & 79,28 & 0,823 & 0,327 & 67,01 \\
\hline 4 & 1 & 1 & -1 & -1 & 127,05 & 0,833 & 0,359 & 62,4 \\
\hline 5 & -1 & -1 & 1 & -1 & 45,76 & 0,761 & 0,324 & 68,55 \\
\hline 6 & 1 & -1 & 1 & -1 & 70,69 & 0,78 & 0,312 & 62,4 \\
\hline 7 & -1 & 1 & 1 & -1 & 131,42 & 0,886 & 0,44 & 68,1 \\
\hline 8 & 1 & 1 & 1 & -1 & 179,46 & 0,901 & 0,405 & 62,03 \\
\hline 9 & -1 & -1 & -1 & 1 & 68,28 & 0,784 & 0,439 & 70,61 \\
\hline 10 & 1 & -1 & -1 & 1 & 111,78 & 0,797 & 0,419 & 62,49 \\
\hline 11 & -1 & 1 & -1 & 1 & 90,56 & 0,769 & 0,411 & 68,66 \\
\hline 12 & 1 & 1 & -1 & 1 & 149,66 & 0,766 & 0,467 & 64,91 \\
\hline 13 & -1 & -1 & 1 & 1 & 84,71 & 0,75 & 0,423 & 68,05 \\
\hline 14 & 1 & -1 & 1 & 1 & 136,52 & 0,782 & 0,45 & 62,71 \\
\hline 15 & -1 & 1 & 1 & 1 & 99,49 & 0,769 & 0,447 & 69,62 \\
\hline 16 & 1 & 1 & 1 & 1 & 170,18 & 0,776 & 0,463 & 64,42 \\
\hline 17 & 0 & 0 & 0 & 0 & 103,05 & 0,828 & 0,393 & 67,06 \\
\hline 18 & 0 & 0 & 0 & 0 & 104,26 & 0,849 & 0,405 & 67,52 \\
\hline 19 & 0 & 0 & 0 & 0 & 103,49 & 0,848 & 0,425 & 67,35 \\
\hline 20 & -2 & 0 & 0 & 0 & 78,79 & 0,763 & 0,362 & 71,5 \\
\hline 21 & 2 & 0 & 0 & 0 & 155,22 & 0,862 & 0,376 & 64,02 \\
\hline 22 & 0 & -2 & 0 & 0 & 53,78 & 0,71 & 0,266 & 68,63 \\
\hline 23 & 0 & 2 & 0 & 0 & 143,50 & 0,751 & 0,42 & 66,76 \\
\hline 24 & 0 & 0 & -2 & 0 & 56,38 & 0,8 & 0,313 & 66,35 \\
\hline 25 & 0 & 0 & 2 & 0 & 142,55 & 0,761 & 0,352 & 65,55 \\
\hline 26 & 0 & 0 & 0 & -2 & 78,05 & 0,813 & 0,333 & 61,34 \\
\hline 27 & 0 & 0 & 0 & 2 & 127,50 & 0,785 & 0,435 & 69,32 \\
\hline
\end{tabular}

Segundo BOX \& DRAPER [4], para que uma regressão não seja apenas estatisticamente significativa, mas também útil para fins preditivos, a razão entre a média quadrática da regressão e a média quadrática do resíduo $\left(\mathrm{MQ}_{\mathrm{R}} / \mathrm{MQ}_{\mathrm{r}}\right.$, que corresponde ao $\left.\mathrm{F}_{\text {calculado }}\right)$ deve ser no minimo 10 vezes maior que o valor de $\mathrm{F}_{1, \mathrm{n}-2}\left(\mathrm{~F}_{\text {tabelado }}\right)$. Conforme Tabela 3, o modelo para a variável independente dureza apresentou bom ajuste $\left(\mathrm{R}^{2}=0,97\right)$ e a razão $\mathrm{F}_{\text {calculado }} / \mathrm{F}_{\text {tabelado }}$ ao nivel de $5 \%$, foi 11,28 , o que indica que esse modelo também é preditivo.

Os modelos das demais respostas também apresentaram bom ajuste, com exceção da coesividade para a qual apenas $63 \%$ da variação total em torno da média foi explicada pela regressão.

TABELA 3. Análise de variância para dureza, elasticidade, coesividade e umidade espremivel

\begin{tabular}{ccccc}
\hline & Dureza & Elasticidade & Coesividade & UE $^{\mathrm{a}}$ \\
\hline $\mathrm{F}_{\text {calculado }}$ & 29,57 & 11,72 & 20,62 & 10,97 \\
$\mathrm{~F}_{\text {tabelado }}{ }^{\mathrm{b}}$ & 2,62 & 2,54 & 3,40 & 2,49 \\
$\mathrm{~F}_{\text {cal }} / \mathrm{F}_{\text {tab }}$ & 11,28 & 4,61 & 6,06 & 4,40 \\
$\mathrm{R}^{2}$ & 0,97 & 0,81 & 0,63 & 0,87 \\
\hline amidade espremivel & & &
\end{tabular}

b à $95 \%$ de confiança $(\mathrm{p} \leq 0,05)$

Os coeficientes de regressão das variáveis do processo, no nivel de significância de 5\%, foram compilados na Tabela 4.

TABELA 4. Coeficientes de regressão para dureza, elasticidade, coesividade e umidade espremivel.

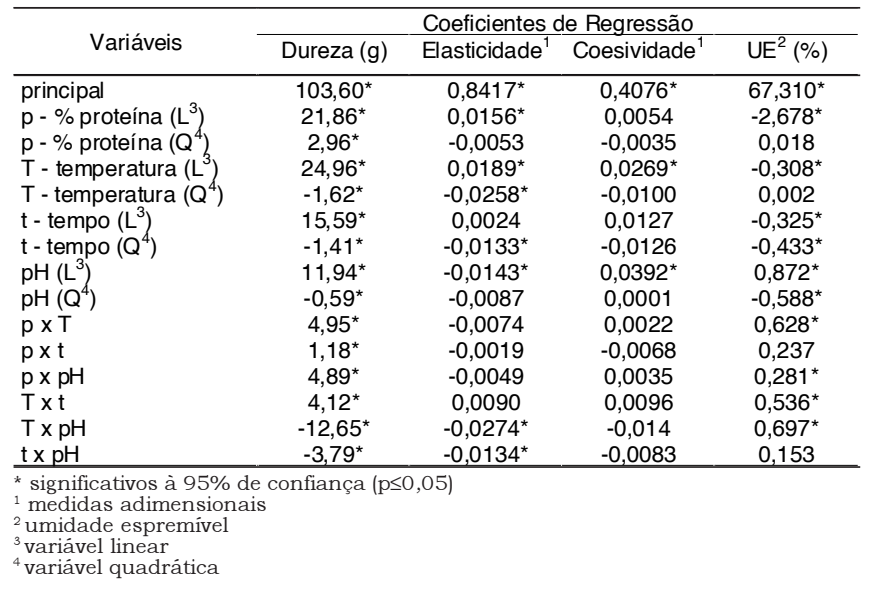

As variáveis lineares, quadráticas e suas interações duas a duas que foram significativas a 95\% de confiança fizeram parte dos modelos para compor as superficies de resposta, sendo as demais excluidas.

Conforme a Tabela 4 todas as variáveis do processo, bem como suas interações foram significativas para a resposta dureza. Por outro lado, apenas temperatura e $\mathrm{pH}$ lineares apresentaram efeito significativo para a coesividade dos géis ácidos de CPS.

A partir das equações foram geradas as superficies de resposta conforme Figuras 1, 2 e 3. 
Para a resposta dureza todas as interações de variáveis resultaram em superficies semelhantes (dureza maior nos niveis superiores de concentração de proteina, $\mathrm{pH}$, temperatura e tempo). Nas interações do $\mathrm{pH}$ com tempo (Figura 1 B) e com temperatura (não publicada) observa-se formação de platô, indicando que a firmeza dos géis contendo $10 \%$ de proteína (ponto central) não tenderá a ultrapassar $160 \mathrm{~g}$ entre as faixas de $\mathrm{pH} 4,9$ a 5,2, tempo de 24 a 27 minutos e temperatura de 85 a $89^{\circ} \mathrm{C}$. No estudo de SHIMADA e CHEFTEL [23] a firmeza dos géis (em pH 7,5) aumentaram proporcionalmente ao tempo de aquecimento, atingindo platô após 30 minutos. Outros autores relataram platô na força dos géis de CPS após 20 minutos a $90^{\circ} \mathrm{C}(4 \%$ proteína e pH 7,0 ) e mesma tendência a $80^{\circ} \mathrm{C}$ após $40 \mathrm{mi}$ nutos [2].
A)

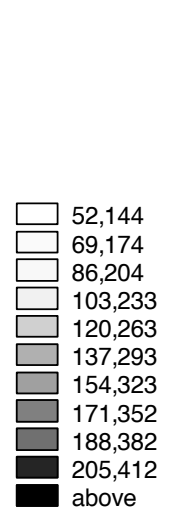

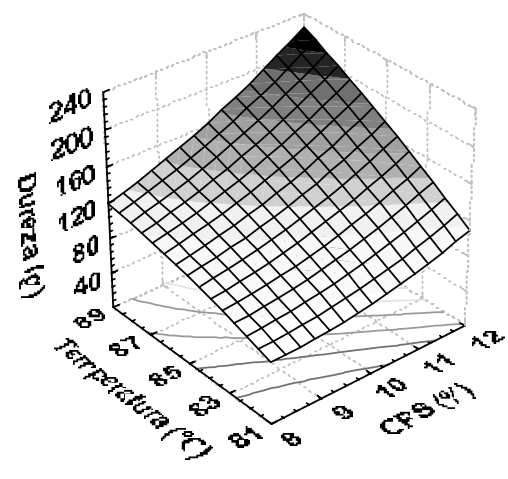

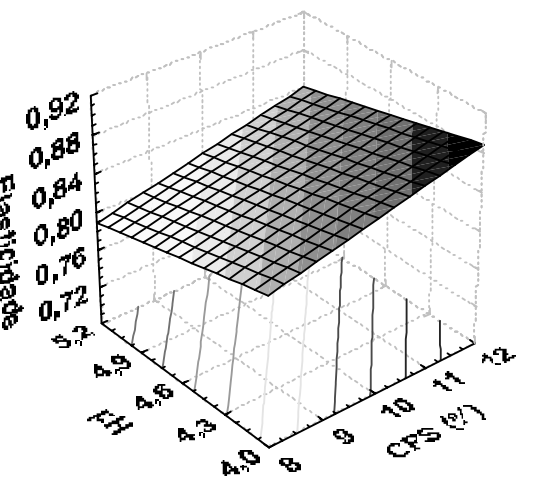

B)

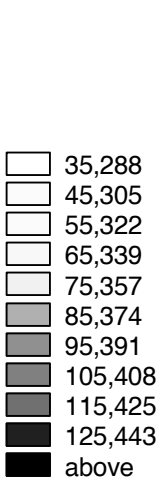

C)

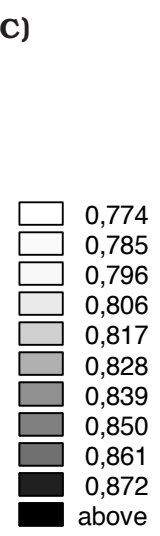

D)

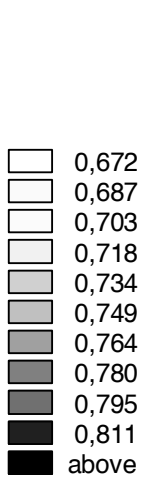

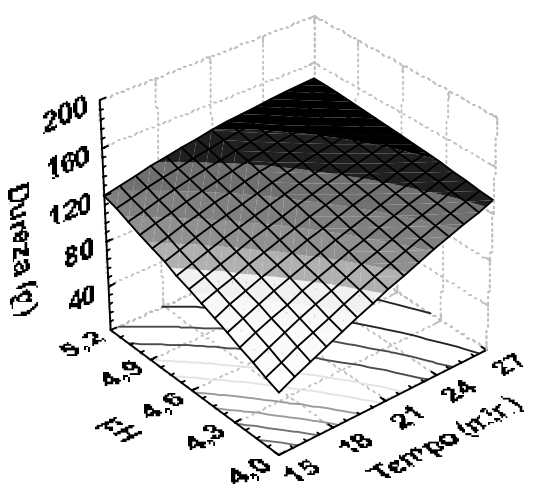

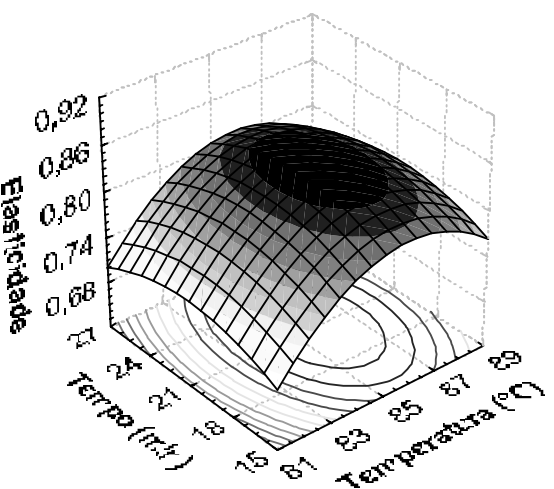

FIGURA 1. Superficies de resposta da temperatura e concentração de proteína do CPS (A) e tempo e pH (B) na dureza dos géis de CPS; pH e concentração de proteína do CPS (C) e tempo e temperatura de desnaturação (D) na elasticidade dos géis de CPS. (Os pares de variáveis que não aparecem nos gráficos foram fixados nos seus respectivos pontos centrais).

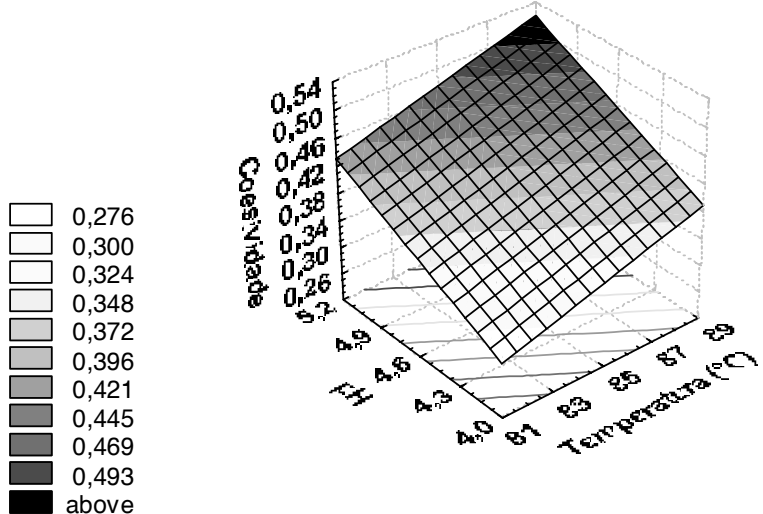

FIGURA 2. Superfície de resposta do pH e temperatura na coesividade dos géis de CPS. (Concentração de proteína do CPS e tempo de desnaturação foram fixados nos seus respectivos pontos centrais). 
A)

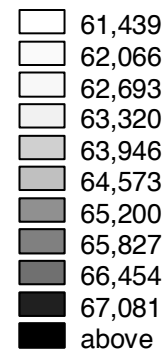

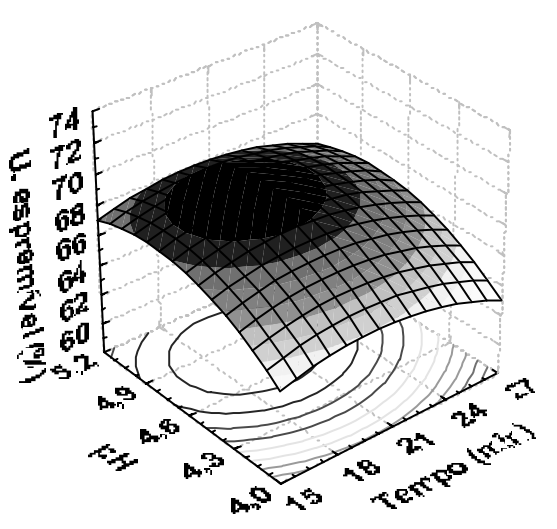

B)

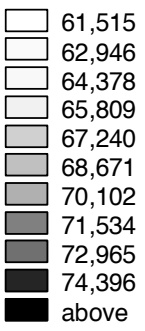

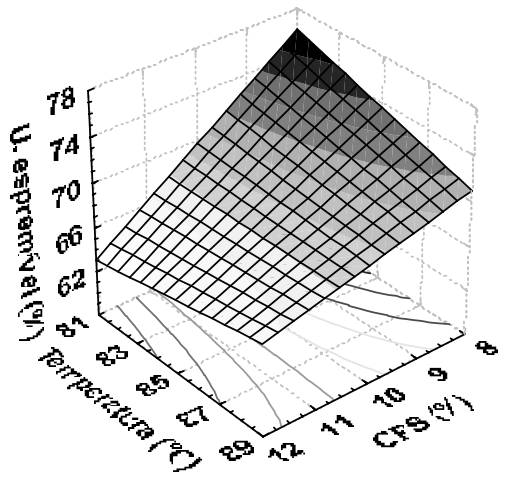

FIGURA 3. Superficies de resposta do pH e tempo (A) e temperatura de desnaturação e concentração de proteína de CPS (B) na umidade espremível dos géis de CPS. (Os pares de variáveis que não aparecem nos gráficos foram fixados nos seus respectivos pontos centrais).

Os géis de CPS mais firmes (acima de 205g) foram obtidos nos maiores valores de concentração protéica e temperatura de desnaturação (Figura 1A). Para o processo de gelatinização das proteínas do CPS é necessária uma concentração minima de proteínas que pode variar entre $6-12 \%$ dependendo do $\mathrm{pH}$ [6] e temperatura entre as faixas de 70 a $90^{\circ} \mathrm{C}$ [17]. A Figura 1A é semelhante à obtida por BOYE, RAMASWAMY \& RAGHAVAN [5] que estudaram a firmeza de géis de CPS avaliando os mesmos parâmetros, embora em faixas mais amplas (10 a 30\% de proteína e 65 a $90^{\circ} \mathrm{C}$ ).

Géis mais elásticos foram obtidos em concentrações maiores de proteína (acima de 11\%). Por outro lado, $\mathrm{pH}$ acima de 4,6 levou à diminuição da elasticidade ( $F \dot{i}$ gura 1C). Embora a elasticidade dos géis seja fortemente relacionada com a formação de pontes S-S intermoleculares [23], interações hidrofóbicas e eletrostáticas predominam na rede dos géis obtidos na faixa isoelétrica de $\mathrm{pH}$ [22], pois, nesses valores de $\mathrm{pH}$ os grupos $\mathrm{SH}$ são relativamente inertes, não contribuindo para manutenção da estrutura do gel [14].

SHIMADA e CHEFTEL [22] obtiveram pequena variação de elasticidade em géis de $\operatorname{CPS}(\mathrm{pH} 7,5)$ com o aumento da concentração de proteína (de 8 para $10 \%$ ) e da temperatura de desnaturação $\left(75\right.$ a $\left.135^{\circ} \mathrm{C}\right)$. Ambas variáveis independentes apresentaram efeito significativo na elasticidade dos géis no presente trabalho, especialmente a última.

Faixa ótima de elasticidade foi obtida quando tempo e temperatura estiveram nos pontos centrais (21 minutos e $85^{\circ} \mathrm{C}$ ), conforme ilustrado na Figura $1 D$.

A coesividade relaciona-se com as forças envolvidas nas ligações internas do produto. As únicas variáveis do processo que influenciaram significativamente a coesividade $(\mathrm{p}<0,05)$ foram temperatura e $\mathrm{pH}$, gerando superficie plana (modelo linear). A tendência da coesividade foi de aumentar paralelamente ao $\mathrm{pH}$ e temperatura (Figura 2) nas faixas estudadas. O maior valor de coesividade no $\mathrm{pH}$ 5,2 coincide com o pI da $\beta$-lactoglobulina (que corresponde de 40 a $77 \%$ das proteinas totais do CPS), sugerindo grande agregação das moléculas protéicas presentes em maior quantidade no produto.

Os valores de umidade espremivel foram altos (cerca de $65 \%$ ), indicando baixa capacidade de retenção de água dos géis ácidos de CPS.

$\mathrm{Na}$ faixa de $\mathrm{pH}$ próxima a 4,6 foi expelida grande quantidade de água das amostras, devido à forte agregação protéica (Figura $3 \mathrm{~A}$ ). Quando o $\mathrm{pH}$ se aproxima de 4,0 a umidade espremivel é atenuada. Durante a produção de iogurte, o pH 4,6 é geralmente fixado para o término da fermentação, no entanto, a pós-acidificação durante a vida-de-prateleira é um fenômeno comum. A adição de CPS potencializaria a capacidade de retenção de água dos iogurtes na medida em que o pH diminuísse, ao longo do período de armazenamento.

Tempo e temperatura constituem um binômio importante no processo de gelatinização das proteinas do soro do leite. Quando as condições de aquecimento são extremas as moléculas de proteína não têm tempo hábil para alinharem-se de forma organizada, resultando em agregados ou precipitados com baixa hidratação [18]. Intervalos de 24 a 27 minutos e 87 a $89^{\circ} \mathrm{C}$ corresponderam aos melhores valores de retenção de água.

Observando-se a Figura $3 A$ e $B$, verifica-se que $\mathrm{pH}$ 4,0 e concentração de proteína acima de $10 \%$ favorecem melhores resultados (vale ressaltar que as faixas de menor umidade espremivel são as de maior capacidade de retenção de água).

O total de superficies geradas foi de 24. A análise delas, uma a uma, leva a conclusão que existem faixas onde as respostas são maximizadas ou minimizadas, conforme o interesse (Tabela 5).

Conforme Tabela 5, a maioria dos parâmetros encontra sua resposta máxima nos seus niveis mais altos. No entanto, o pH não apresenta a mesma concordância. Os valores próximos a 4,0 são favoráveis à elasticidade e ao aumento da capacidade de retenção de água, enquanto 
que próximo a $\mathrm{pH} 5,0$ ocorre aumento de firmeza e coesividade. Para optar entre uma faixa ou outra é recomendado, portanto, avaliar as características de interesse no produto. Além disso, ressalta-se que em um alimento os outros componentes do sistema apresentam grande influência no perfil de textura e retenção de água.

TABELA 5. Niveis das variáveis do processo correspondente as maiores respostas para géis ácidos de CPS.

\begin{tabular}{ccccc}
\hline \multirow{2}{*}{ Variável } & \multicolumn{4}{c}{ Níveis } \\
& CPS $(\%)$ & Temperatura $\left({ }^{\circ} \mathrm{C}\right)$ & Tempo $(\min )$ & $\mathrm{pH}$ \\
\hline Dureza & $11-12$ & $87-89$ & $24-27$ & $4,9-5,2$ \\
Elasticidade & $11-12$ & $85-87$ & 21 & 4,0 \\
Coesividade & - & $87-89$ & - & $4,9-5,2$ \\
CRA $^{1}$ & $11-12$ & $87-89$ & $24-27$ & 4,0 \\
\hline${ }^{1}$ capacidade de retenção de água & & &
\end{tabular}

Para produção de iogurte sugerem-se condições que aumentem a capacidade de retenção de água para inibir a sinérese. Para um iogurte de consistência firme (set) valores altos de dureza, elasticidade e coesividade são indicados.

\section{4 - CONCLUSÕES}

Através dos resultados obtidos para géis ácidos de CPS verificou-se:

Géis de CPS com concentração protéica entre 11 e $12 \%$ são mais firmes, elásticos e capazes de reter maiores quantidades de água quando comparados aos contendo de 8 a $10 \%$ de proteína. A coesividade não foi alterada de modo significativo pela concentração de proteína, nas faixas avaliadas.

Quando a temperatura de desnaturação utilizada foi entre 87 a $89^{\circ} \mathrm{C}$, os géis de CPS apresentaram maior dureza, coesividade e capacidade de retenção de água. Para obter géis mais elásticos a faixa ideal de temperatura de desnaturação foi de 85 a $87^{\circ} \mathrm{C}$.

O tempo de aquecimento de 24 a 27 minutos resultou em géis mais firmes. Para a característica elasticidade o tempo ideal foi de 21 minutos. Coesividade e retenção de água não encontraram correlação com o tempo de aquecimento na faixa estudada.

Géis preparados em valores de $\mathrm{pH}$ próximos de 4,0 apresentaram-se mais elásticos e com maior retenção de água, enquanto que os preparados em $\mathrm{pH}$ variando de 4,9 a 5,2 formam géis mais firmes e coesos.

\section{5 - REFERÊNCIAS BIBLIOGRÁFICAS}

[1] AGUilera, J.M. Gelation of whey proteins. Food Technology, v. 49, n. 10, p. 83-89, 1995.

[2] BARBut, S., FOEGEDING, E. A. $\mathrm{Ca}^{2+}$ induced gelation of pre-heated whey protein isolate. Journal of Food Science, v. 58, n. 4, p. 867-871, 1993.

[3] BEUSCHEL, B.C.; CULBERTSON, J.D.; PARTRIDGE, J.A.; SMITH, D. Gelation and emulsion properties of partially insolubilized whey protein concentrates. Journal of Food Science, v. 57, n. 3, p. 605-609, 1992.
[4] BOX, G.E.P.; DRAPER, N.R. Empirical Model-Building and Response Surfaces. New York, Wiley, 1987.

[5] BOYE, J.I.; RAMASWAMY, H.; RAGHAVAN, V.G.S. Interactive effects of factors affecting gelation of whey proteins. Journal of Food Science, v. 62, n. 1, p. 5765, 1997.

[6] BRANDEnBERG, A.H.; MORR, C.V.; WEller, C.L. Gelation of commercial whey protein concentrates: effect of removal of low-molecular-weight components. Journal of Food Science, v. 57, n. 2, p. 427-432, 1992.

[7] COOPER, H.R.; HUGHES, I.R.; MATTHEWS, M.E. Application of response surface methodology to the evaluation of whey protein gels systems. New Zealand Journal of Dairy Science and Technology, v. 12, n. 4, p. 248-252, 1977.

[8] FRIEDMAN, H.H.; WHITNEY, J.E.; SZCZESNIAK, A.S. The texturometer - a new instrument for objective texture measurement. Journal of Food Science, v. 28, n.4, p. 390-396, 1963.

[9] GOSSETT, P.W.; RIZVI, S.S.H.; BAKER, R.C. Qualitative analysis of gelation in egg protein systems. Food Technology, v. 38, n. 5, p. 67-74, 96, 1984.

[10] JAUREGUI, C.A.; REGENSTEIN, J.M.; BAKER, R.R.A. Simple centrifugal method for measuring expressible moisture, a water-binding property of muscle foods. Journal of Food Science, v. 46, n. 4, p. 1271-1273, 1981.

[11] KINSELLA, J.E. Milk proteins: physicochemical and functional properties. Critical Reviews in Food Science and Nutrition, v. 21, n. 2, p. 197-262, 1984.

[12] KOHNHORST, A.L.; MANGINO, M.E. Prediction of the strength of whey protein gels based on composition. Journal of Food Science, v. 50, n. 5, p. 1403-1405, 1985.

[13] MANGino, M.E. Physicochemical aspects of whey protein functionality. Journal of Dairy Science, v. 67, n. 11, p. 2711-2722, 1984.

[14] MANGINO, M.E.; KIM, J.H.; DUNKERLEY, J.A.; ZADOW, J.G. Factors important to the gelation of whey protein concentrates. Food Hydrocolloids, v. 1, n. 4, p. 277-282, 1987.

[15] MANGINO, M.E. Gelation of whey protein concentrates. Food Technology, v. 46, n. 1, p. 114-117, 1992.

[16] MOLDER, H.W.; EMMONs, D.B. Properties of whey protein concentrate prepared by heating under acidic conditions. Journal of Food Science, v. 60, n. 2, p. 177-184, 1976.

[17] MORR, C.V.; HÁ, Y.W. Whey protein concentrates and isolates: processing and functional properties. Food Science and Nutrition, v. 33, n. 6, p. 431-476, 1993.

[18] MUlvihill, D.M.; KINSElla, J.E. Gelation characteristics of whey proteins and b-lactoglobulin. Food Technology, v. 41, n. 9, p. 102-111, 1987.

[19] NETO, B.B.; SCARMINIO, I.S.; BRUNS, R.E. Planejamento e Otimização de Processos. Campinas, SP: Editora da UNICAMP (Série Manuais), 1995.

[20] RATTRAY, W.; JELEN, P. Thermal stability of skim milk/whey protein solution blends. Food Research International, v. 30, n. 5, p. 327-334, 1997.

[21] SCHMIDT, R.H.; ILLINGWORTH, B.L.; AHMED, E.M. Heatinduced gelation of peanut protein/whey protein blends. Journal of Food Science, v. 43, n 2, p. 613-615, 1978.

[22] SHIMADA, K.; CHEFTEL, J.C. Texture characteristics, protein solubility, and sulphydryl group/disulfide bond content of heat-induced gels of whey protein isolate. Journal of Agricultural and Food Chemistry, v. 36, n. 5, p. 1018-1025, 1988. 
[23] SHIMADA, K.; CHEFTEL, J.C. Sulfhydryl group/disulfide bond interchange reaction during heat-induced gelation of whey protein isolate. Journal of Agricultural Food and Chemistry, v. 37, n.1, p. 161-168, 1989.

[24] ZIEGLER, G.R.; FOEGEDING, E.A. The gelation of proteins. Advances in Food and Nutrition Research, v. 34, p. 203-298, 1990.

\section{6 - AGRADECIMENTOS}

Os autores agradecem ao CNPq pela concessão da bolsa de estudos e à FAEP/UNICAMP pelo apoio financeiro ao projeto de pesquisa. 